\title{
Diversity of the Troponin C Genes during Chordate Evolution ${ }^{1}$
}

\author{
Hajime J. Yuasa, ${ }^{*}$ Jos A. Cox, ${ }^{\dagger}$ and Takashi Takagi ${ }^{*, 2}$ \\ ${ }^{*}$ Biological Institute, Graduate School of Science, Tohoku University, Sendai, Miyagi 980-8578; and ${ }^{\dagger}$ Department \\ of Biochemistry, University of Geneva, $\mathrm{CH}-1211$ Geneva 4, Switzerland
}

Received for publication, January 26, 1998

\begin{abstract}
To elucidate the diversity of troponin $\mathrm{C}$ (TnC) during chordate evolution, we determined the organization of TnCs from the amphioxus, the lamprey, and the frog. Like the ascidian, the amphioxus possesses a single gene of $\mathrm{TnC}$, and the fundamental gene structure is identical with the ascidian TnC. However, because alternative splicing does not occur in amphioxus, the potential for generation of $\mathrm{TnC}$ isoforms through this event arises only in the ascidian lineage. From the frog Xenopus laevis, two distinct cDNAs encoding fTnC isoforms and a single s/cTnC cDNA were determined. The duplication of the fTnC gene may be a character of only Xenopus or closely related species. The lamprey possesses two cDNAs each encoding fTnC and s/cTnC. The lamprey is the earliest diverged species among vertebrates, and thus it is supposed that the presence of both $\mathrm{fTnC}$ and $\mathrm{s} / \mathrm{cTnC}$ is universal among vertebrate species, and that the gene duplication might have occurred at a vertebrate ancestor after the protochordate/vertebrate divergence. The position of the 4 th intron is 3.24/0 in protochordate $\mathrm{TnC}$ genes, but at $3.11 / 2$ in vertebrate $\mathrm{fTnCs}$ and $\mathrm{s} / \mathrm{cTnCs}$. It is suggested that the 4th intron sliding might have occurred prior to the gene duplication.
\end{abstract}

Key words: amphioxus, evolution, frog, lamprey, troponin C.

Muscle tissue is morphologically classified into two main types: striated muscle and smooth muscle. The contraction trigger of both types of muscle is identical, an increase in intracellular $\mathrm{Ca}^{2+}$ concentration, but the regulation systems of contraction are different. In general, striated muscle contraction is controlled by troponin complex, consisting of three protein components, troponin C, I, and T ( TnC, TnI, and TnT). On the other hand, smooth muscle contraction is mainly regulated by calmodulin-dependent myosin light chain kinase, which phosphorylates the myosin regulatory light chain. These schemes appear to be universal for vertebrates muscles, as no exception has been observed.

$\mathrm{TnC}$ belongs to the $\mathrm{EF}$-hand $\mathrm{Ca}^{2+}$ binding protein family and functions as the $\mathrm{Ca}^{2+}$ sensor of troponin complex. Two distinct isoforms of $\mathrm{TnC}$, fast skeletal $\mathrm{TnC}(\mathrm{f} T \mathrm{TC}$ ) and slow/cardiac TnC (s/cTnC), have been identified in mammalian and avian muscles. The former is expressed only in fast skeletal muscle, and the latter in both slow skeletal and heart muscles. These two TnC isoforms are encoded by independent genes, and the gene structures of these isoforms in human and mouse have been determined (1-4). In lower vertebrates, few sequences of $\mathrm{TnC}$ have been deter-

\footnotetext{
The determined nucleotide sequences have been submitted to the DDBJ under the accession numbers D88976 $(B$. lanceolatum TnC cDNA), D88977 (B. floridae TnC cDNA), D88978 (B. lanceolatum TnC genome), AB003078 ( $X$. laevis $\mathrm{fTnC} \alpha$ cDNA), AB003079 ( $X$. laevis $\mathrm{fTnC} \beta$ cDNA), $\mathrm{AB003080}$ ( $X$. laevis $\mathrm{s} / \mathrm{cTnC} \mathrm{cDNA}$ ), $\mathrm{AB} 008555$ (E. japonicus fTnC cDNA), and $\mathrm{AB} 008556$ (E. japonicus $\mathrm{s} / \mathrm{cTnC}$ cDNA).

2 To whom correspondence should be addressed. Tel: +81.22-217. 6677, Fax: +81-22-263-9206, E-mail: ttakagi@ mail.cc.tohoku.ac.jp

(C) 1998 by The Japanese Biochemical Society.
}

mined: fTnC from the frog Rana esculenta (5) and the eel Anguilla anguilla (6), and $\mathrm{s} / \mathrm{cTnC}$ from the salmon Oncorhynchus mykiss (7). Because the two $\mathrm{TnC}$ isoforms were isolated from bony fishes, it is supposed that the presence of the $\mathrm{f} T \mathrm{Tn}$ and $\mathrm{s} / \mathrm{cTnC}$ is general for Osteichthyes. However, the isolation of both TnC isoforms from a single species of fish has not been reported. In addition, no data is available $\mathrm{TnC}$ from Chondrichthyes or Agnatha.

The invertebrate chordates (also called protochordates) are composed of two subphyla, Urochordata and Cephalochordata, and are the closest species to vertebrates. The ascidian, often called the sea squirt, is a sessile tunicate belonging to Urochordata, which undergoes a radical metamorphosis during development from a tadpole-like larva to a sessile adult. The ascidian possesses three different types of muscle tissue: monocellular striated muscle of the larval tail $(8)$, multinucleate smooth muscle of the adult body wall $(9,10)$, and unicellular striated muscle of the adult heart (11). On the other hand, the amphioxus, belonging to Cephalochordata, does not undergo metamorphosis during development. Therefore, throughout life, the amphioxus possesses only one type of muscle, monocellular striated tail muscle (12).

The ascidian body wall muscle, although a smooth muscle, contains troponin complex that regulates muscle contraction as in striated muscle (13). Recently, we have isolated the cDNAs of two $\mathrm{TnC}$ isoforms from the ascidian Halocynthia roretzi and determined their genomic structure (14). These two isoforms, which are the products of differential RNA processing from a single gene, do not parallel those of higher vertebrates: one is larval $\mathrm{TnC}$, expressed in larval striated muscle, and the other is adult $\mathrm{TnC}$, present in heart muscle and body wall smooth muscle. The intron localization of the ascidian $\mathrm{TnC}$ gene is identical 
to that of the vertebrate $\mathrm{s} / \mathrm{cTnCs}$ except for the 4th intron. We have also reported the primary structure of amphioxus $\mathrm{TnC}$ and its $\mathrm{Ca}^{2+}$ binding characterization (15). However, it is unknown whether the other $\mathrm{TnC}$ isoform is present in amphioxus.

In this study, we attempt to elucidate the diversity of TnC during chordate evolution by comparing the intron localization of $\mathrm{TnC}$ genes. First, we determine the $\mathrm{TnC}$ cDNAs from two species of amphioxus in different developmental stages, the adult of Branchiostoma lanceolatum and the larva of $B$. floridae, and the genomic structure of $B$. lanceolatum $\mathrm{TnC}$. Second, we isolate the cDNAs of $\mathrm{TnC}$ isoforms from the lamprey Entosphenus japonicus and the frog Xenopus laevis. The positions of some introns of these $\mathrm{TnC}$ genes are also determined.

\section{MATERIALS AND METHODS}

Cloning of Amphioxus Troponin C cDNAs and Genomic $D N A$ - Total RNA of adult $B$. lanceolatum was prepared by the acid guanidium thiocyanate method (16), and mRNA was purified with an Oligotex dT-30 Super (Japan Roche). Single-stranded cDNA was synthesized using a FirstStrand cDNA Synthesis Kit (Pharmacia). The cDNA library of $B$. floridae was constructed in $\lambda$ ZAP II (Stratagene) using mRNA prepared from 2-4-day-old larvae (12). The $3^{\prime}$-half of $B$. lanceolatum $\operatorname{TnC}$ cDNA was amplified by polymerase chain reaction (PCR) (17) using Ex Taq DNA polymerase (Takara). The redundant oligomer used for PCR was 5'-CARGARATGATHGARGARGTNGA-3', where $R$ represents $A$ and $G ; H, A, C$, and T; N, A, C, G, and $\mathrm{T}$. This was originally designed based on the amino acid sequence QEMIEEVD (residue 51-58) of ascidian $\mathrm{TnC}$ (18). This primer was also useful for amplification of amphioxus $\mathrm{TnC}$, the corresponding sequence of amphioxus being QQMIDEVD (residue 57-64) (15). The oligo-dT adaptor $5^{\prime}$-GGGATCCGAATTCT ${ }_{17}-3^{\prime}$ was used as another primer.

The $5^{\prime}$-upstream stretch of cDNA was determined as follows. The EcoRI-ended double-stranded cDNA was synthesized from mRNA using a TimeSaver cDNA Synthesis Kit (Pharmacia). The EcoRI Cassette (Takara) was ligated each end of cDNA. The $5^{\prime}$-upstream region was amplified by PCR using cassette-specific primer $\mathrm{C} 1,5^{\prime}$.GT. ACATATTGTCGTTAGAACGCG-3', and R1 (Table I).

TABLE I. Primers used for amplification of $B$. lanceolatum TnC genomic DNA fragments.

\begin{tabular}{|c|c|}
\hline $\begin{array}{l}\text { Primers (positions } \\
\text { for cDNA sequence) }\end{array}$ & Sequence \\
\hline \multicolumn{2}{|l|}{ Sense primers } \\
\hline F3 $(-33$ to -14$)$ & TCTGGCTGTCCGTGATAAAG \\
\hline F4 (35 to 54$)$ & TCAAGGAGGAGCAGATCTCC \\
\hline F2 (239 to 258$)$ & TGGCCAGGGCCATGCAGGAC \\
\hline F1 (380 to 400$)$ & ACTTGACAGATGATGAGCTCC \\
\hline F5 (within intron $5^{\mathrm{a}}$ ) & cggcgagcctgatggtaaag \\
\hline \multicolumn{2}{|l|}{ Antisense primers } \\
\hline R6 (within intron $2^{b}$ ) & cacgtgactgtgtcageceg \\
\hline $\mathrm{R} 3$ (274 to 293 ) & GCACGTAGCTCATCGTCGGG \\
\hline $\mathrm{R} 2(423$ to 442$)$ & ACCTCCCGTCCCTGTTTCCG \\
\hline $\mathrm{R} 7$ (475 to 494$)$ & CTACCACCGGACCTTCAGTT \\
\hline $\mathrm{R} 1$ (939 to 962$)$ & ACTGGAGACCAGGTTTATTAAAGG \\
\hline
\end{tabular}

The $B$. floridae TnC cDNA was also amplified by PCR using a cDNA library as template. Primers used for $3^{\prime}$-half amplification were $\mathrm{F} 4$ and T7 primer, $5^{\prime}$-TAATACGACTCACTATAGGG-3', and those for $5^{\prime}$-half amplification were R2 and T3 primer, 5' -ATTAACCCTCACTAAAGGGA-3' (Table I).

The B. lanceolatum genomic DNA used for PCR amplification was prepared from a crude nuclei fraction, obtained as the precipitate of muscle protein preparation (15), by the conventional phenol-chloroform method. Several sets of primers were used to amplify the genomic DNA fragment by PCR. The primers were designed based on the cDNA or genomic sequence of $B$. lanceolatum $\mathrm{TnC}$ as listed in Table I. The strategy of amplification of the B. lanceolatum $\mathrm{TnC}$ gene is shown in Fig. 3. All the amplified products were subcloned to $\mathrm{pCR}$ II plasmid vector (TAcloning kit, Invitrogen) or pUC18 for sequencing. The sequences of products were determined by the dideoxy chain termination method with Dye Primer Cycle Sequencing Kit (Applied Biosystems) using an automated DNA sequencer (Applied Biosystems 373A).

Southern Hybridization-For Southern blot analysis, the genomic DNA was prepared from a single specimen of lyophilized $B$. lanceolatum by the conventional phenolchloroform method. To remove polysaccharides, the genomic DNA was loaded on a DEAE-cellulose column $(1 \times 0.5$ $\mathrm{cm})$ which was equilibrated with TE buffer $(10 \mathrm{mM}$ Tris$\mathrm{HCl}, \mathrm{pH} 8.0,1 \mathrm{mM}$ EDTA), and the column was washed with 10 volumes of TE buffer. The genomic DNA was eluted with $\mathrm{TE}$ buffer containing $1 \mathrm{M} \mathrm{NaCl}$ and concentrated by ethanol precipitation. The restriction enzyme-digested genomic DNA was separated on $0.7 \%$ agarose gels and transferred to nylon membranes. For the probe DNA, the $527 \mathrm{bp}$ TnC cDNA was labeled with DIG-DNA Labeling Mixture (Boehringer Mannheim) by PCR using primers F3 and R7 (see Table I). Hybridization and washing were carried out according to the manufacturer's instructions

TABLE II. Primers used for amplification of Xenopus and Entosphenus TnC cDNAs and genomic DNA fragments.

\begin{tabular}{|c|c|}
\hline $\begin{array}{l}\text { Primers (positions } \\
\text { for cDNA sequence) }\end{array}$ & Sequence \\
\hline \multicolumn{2}{|l|}{ For Xenopus f $\mathrm{TnC} \alpha$} \\
\hline $\mathrm{X}$ f F $1(-21$ to -4$)$ & AGCTCTGTGTCCATTGCC \\
\hline $\mathrm{X}$ f F2 (272 to 291$)$ & CGCAGGGAAAAAGTGAAGAG \\
\hline $\mathrm{X}$ f $\alpha \mathrm{R} 1$ (930 to 949$)$ & GAGTAGGCAGCTCTCTAGAG \\
\hline$X$ f R2 (77 to 94$)$ & GAGGAAGGACCTCGCATC \\
\hline X f R3 (379 to 398$)$ & TCATCTGTGATGCTCTCCCC \\
\hline \multicolumn{2}{|l|}{ For Xenopus $\mathrm{fTnC} \beta$} \\
\hline $\mathrm{X} f \beta \mathrm{R} 1$ (912 to 931$)$ & GAGAGTGATGTGCACATCAG \\
\hline \multicolumn{2}{|l|}{ For Xenopus s/cTnC } \\
\hline X s/c F1 (266 to 285$)$ & GCAAAGGAAAATCAGAAGAA \\
\hline $\mathrm{X}$ s/c R1 (673 to 692$)$ & ACTGTTAACAAAGAATTTCC \\
\hline X s/c R2 (373 to 392) & TCTTCTGTAATTGTCTCTCC \\
\hline \multicolumn{2}{|l|}{ For Entosphenus fTnC } \\
\hline E f F1 $(-20$ to -1$)$ & ACAACCCCTTACCAAGTACC \\
\hline E f F2 (278 to 297$)$ & CGGCCGGCCAGACGGAGGAG \\
\hline E f R1 (505 to 524$)$ & TCGGTCCACGGTCCACCTGA \\
\hline E f R2 (385 to 404$)$ & AGGTCCGTGACGTTCTCGCC \\
\hline \multicolumn{2}{|l|}{ For Entosphenus s/cTnC } \\
\hline E s/c F1 (269 to 288$)$ & GCAAGGGGAAGTCAGAAGAG \\
\hline E s/c R1 (490 to 509$)$ & GGGTATACGGAAGATTCCCA \\
\hline $\mathrm{E} \mathrm{s} / \mathrm{c}$ R2 (376 to 395$)$ & TCGTCTGTGATGTCCTCCCC \\
\hline
\end{tabular}

Vol. 123 , No. 6,1998 
$\begin{array}{llllllllllllllllllllllllllllll}M & S & D & D & Y & V & K & A & R & V & M & F & K & E & E & Q & I & S & E & F & K & M & A & F & D & M & F & D & E & D\end{array}$ ATGTCGGACGACTATGTCAAGGCTCGGGTGATGTTCAAGGAGGAGCAGATCTCCGAGTTCAAGATGGCGTTTGACATGTTCGACGAGGAT

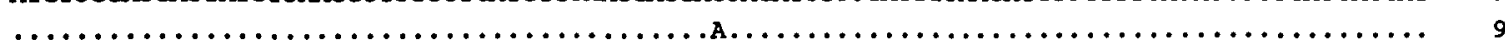

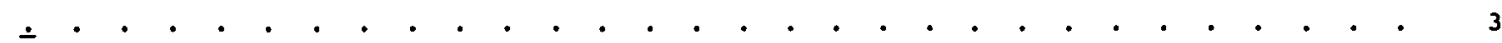

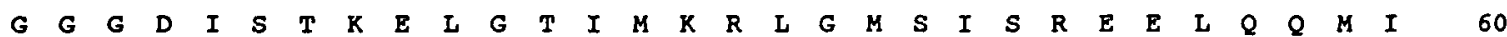
GGCGGTGGTGACATCAGCACTAAGGAGTTGGGCACGATCATGAAGAGGCTGGGCATGAGCATCTCCAGAGAGGAGCTGCAGCAGATGATC 180

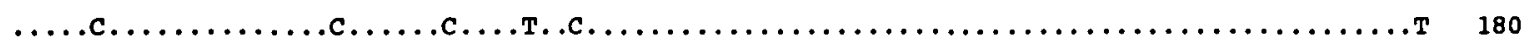

\section{$\downarrow$}

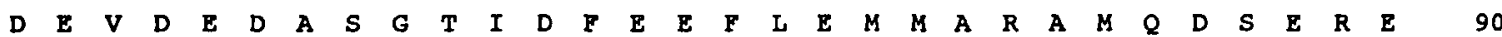
GACGAGGTGGACGAGGACGCCAGCGGTACCATCGACTTCGAGGAGTTCTTGGAGATGATGGCCAGGGCCATGCAGGACAGTGAGCGTGAG 270

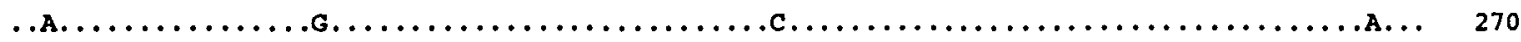

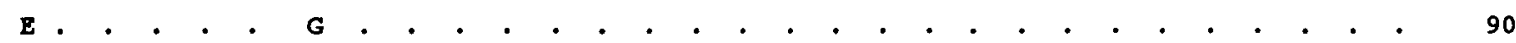

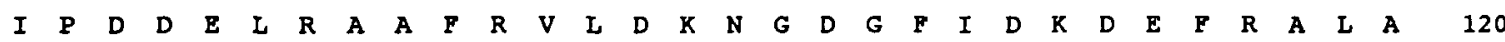
ATTCCCGACGATGAGCTACGTGCAGCCTTCAGGGTCTTGGACAAGAACGGAGATGGTTTCATCGACAAGGACGAGTTCCGCGCCCTAGCA 360

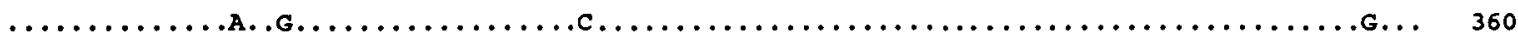

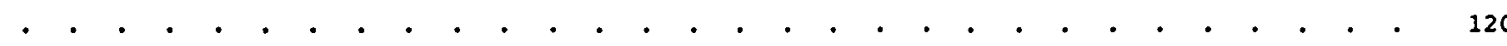

\begin{tabular}{lllllllllllllllllllllllllllllllll}
\hline & $E$ & $C$ & $A$ & $G$ & $D$ & $D$ & $L$ & $T$ & $D$ & $D$ & $E$ & $L$ & $H$ & $E$ & $F$ & $M$ & $D$ & $E$ & $Y$ & $D$ & $G$ & $N$ & $R$ & $D$ & $G$ & $R$ & $F$ & $D$ & $Y$ & 150
\end{tabular} TCAGAGTGCGCCGGTGATGACTTGACAGATGATGAGCTCCATGAGTTTATGGACGAGTACGACGGAAACAGGGACGGGAGGTTTGACTAT 450

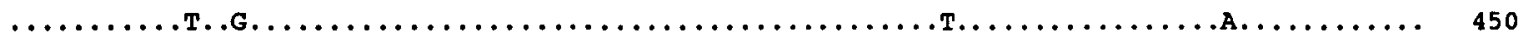

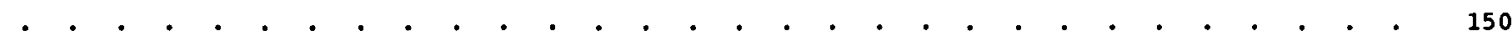

1

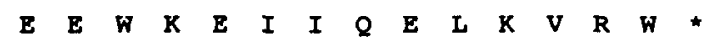

GAGGAGTGGAAAGAGATCATCCAGGAACTGAAGGTCCGGTGGTAGAAACTTCCAGCCGCCATCTTATCCGCCATCTTCAAAGCAACATAC ............C.T..........................A..AC.................. 539 . . . . I . . . . I . . *

AGCCTTCCGCATGCGCGAGGAAGTTCCTCACAGT-CCGGCGGGCC-TAGCTGACACACCGGCCGCTACAGACGACCTGACCACGCCCAAA 628 ...............CC.C....G...T...G..A..AG.......CA..T.......G......... 628

CTAATTCAGCTTTCTWTACGCCACTCTGCACTACAATCGTGTTTGTTTTGAACTTATTTTGTCTAGATTGTGTATTATAG--TTTAAT 716

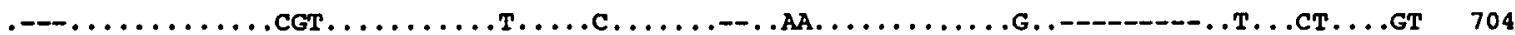
...........G..........................GC.A..G.AA..C...A......TCT... 794

Fig. 1. Comparison of cDNA and derived amino acid sequences of $B$. lanceolatum and $B$. floridae TnCs. Upper, B. lanceolatum (adult) TnC cDNA and the deduced amino acid sequences; lower, $B$. floridae (larva) TnC cDNA and the deduced amino acid sequence. Identical nucleotides and amino acids to those in $B$. lanceolatum are indicated by dots (.). Gaps are inserted for maximal similarity and shown by bars $(-$ ). The typical polyadenylation signal (AATAAA) is underlined. The N-terminal Met (also underlined) is removed after translation. The arrows indicate the positions of introns in $B$. lanceolatum $\mathrm{TnC}$ gene. 
(Boehringer Mannheim), and the TnC gene was detected with a DIG Luminescent Detection Kit (Boehringer Mannheim).

Isolation of Lamprey TnC and Protein Sequence Determination-The lamprey f'TnC was prepared from white muscle, and the sequences of the peptides digested with lysyl endopeptidase were determined as previously described (19).

Cloning of Frog and Lamprey Troponin $C$ cDNAs and Partial Genomic DNA-Poly(A) ${ }^{+}$RNA was independently purified from the white muscle and heart of the frog $X$. laevis and the lamprey $E$. japonicus, and the single-stranded cDNA was synthesized as described above. The 3'halves of Xenopus and Entosphenus TnC isoform cDNAs were amplified by PCR using the oligo-dT adaptor and the redundant oligomer 5'-GARTTYAARGCNGCNTTYGA$3^{\prime}$, designed based on the consensus sequence among the vertebrates TnCs, EFKAAFE (1st-7th residues of site I, the first EF-hand site).

The 5 -upstream regions of Xenopus fTnC and s/cTnC cDNAs were amplified as in the case of amphioxus. The primers used were cassette-specific primer $\mathrm{C} 1$ and a nonredundant primer, X f $\alpha$ R1 (for Xenopus fTnC $\alpha$ cDNA), X f $\beta$ R1 (for Xenopus fTnC $\beta$ cDNA), or X s/c R1 (for Xenopus s/cTnC cDNA). The $5^{\prime}$-upstream regions of Entosphenus cDNAs were amplified by the 5'-RACE method (20). Reverse transcription was primed with $\mathrm{E} f \mathrm{R} 1$ (for Entosphenus fTnC cDNA) or E s/c R1 (for Entosphenus s/cTnC cDNA) and the poly-A tail was added to the $3^{\prime}$-end of cDNA with terminal deoxynucleotidyl-transferase (Takara). The PCR amplifications were performed with primer sets of oligo-dT adaptor and E $\mathrm{f}$ R2 (for Entosphenus fTnC cDNA) or E s/c R2 (for Entosphenus s/cTnC cDNA). The primer sequences are listed in Table II.

The genomic DNAs of the frog and the lamprey were prepared from their white muscles by the phenol-chloroform method. The $\mathrm{N}$-terminal coding region of Xenopus fTnC $\alpha$ was amplified by PCR with primers X $f \mathrm{~F} 1$ and $\mathrm{X} f$ R2. The site III regions of the frog and the lamprey TnCs genes were also amplified by PCR using primer sets of $\mathrm{X} \mathrm{f}$ $\mathrm{F} 2$ and $\mathrm{X}$ f R3 (for Xenopus fTnC $\alpha$ gene), $\mathrm{X}$ s/c F1 and X s/c R2 (for Xenopus s/cTnC gene), E f F2 and E f R2 (for
Entosphenus fTnC gene), and E s/c F1 and E s/c R2 (for Entosphenus s/cTnC gene). The primers sequences and positions for cDNA are listed in Table II.

\section{RESULTS AND DISCUSSION}

$c D N A$ and Genomic Structure of TnC from Two Species of Amphioxus-The cDNA of $B$. lanceolatum $\mathrm{TnC}$ was amplified by PCR and the complete cDNA sequence of 1,013 nucleotides was constructed from two overlapping fragments (Fig. 1). The open reading frame is composed of 495 nucleotides and encodes a protein of 163 amino acid residues as the initial Met is removed after translation (15). Several amino acid differences are observed as compared with previously reported $B$. lanceolatum $\mathrm{TnC}$ amino acid sequence (15); His replaces Leu at residue 134; Asp replaces Met at residue 138; and Glu replaces Asp at residue 139 . These are probably caused by peptide sequencing error, because the cDNA sequence is identical to

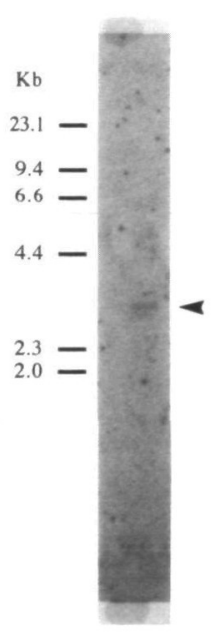

Fig. 2. Southern blot analysis of the B. lanceolatum ThC gene. Genomic DNA prepared from a single specimen of lyophilized $B$. lanceolatum was digested with EcoRI and hybridized to the DIGlabeled TnC cDNA. Left, size markers in $\mathrm{kb}$.
Fig. 3. Structure of the B. lanceolatum TnC gene and strategies used for PCR amplification of DNA fragments. a: EcoRI (E) cleavage sites. The fragment indicated by an asterisk may correspond to the band of $3.0 \mathrm{kbp}$ detected by Southern blot analysis (Fig. 2). b: Exon/intron map of the $B$. lanceolatum TnC gene. Exons (Ex1-Ex6) and introns $(\operatorname{In} 1-\operatorname{In} 5)$ are shown in boxes and thin bars, respectively. c: Strategies used for PCR amplification. The primers used for PCR are shown in Table $I$.

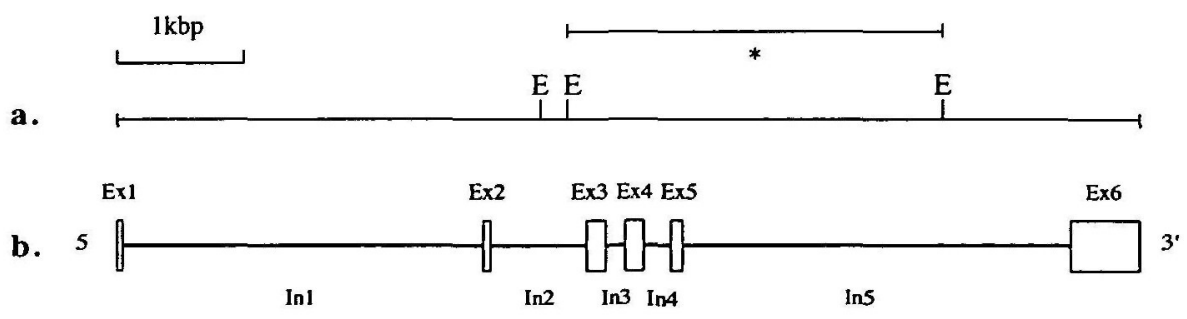

c. $\mathrm{F}^{3} \rightleftharpoons$

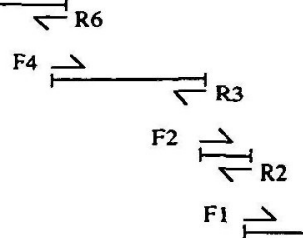

F5 $\longrightarrow$ $\Gamma_{R 7}^{-1}$

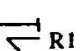


TCTGGCTGTCCGTGATAAAGAAGTCCACCAAACATG gacccggatttagcatagttaggacagcgtgaattgtggccaaggttgtatgtatgccttgtgacagaaagggaacgcgctcctgtttctggtgcttctg 200 tcagaagtcagacaatgccaatgtagacagtgtggtataacggcgtttctaaacttataatcctaattgagccagcagggtgcgttgggtttcttgtat 300 gacttgcagtttgtagaattaatctgtaaccatagagaacaagactacgagtggtcattaatcctcaacatagaggttgagagtagaagcagcagatt 400 ttaccgagagataatttccagggatagtgatgtgatatcgtctcggagatgccacaatgtcagctccgctattcacggcatggcgcatagcaggcgcca 500 tatttggcactagagcacgaccccttggtcttcggttccatccttttgaacacatgcataactcttaaacggccttaacaagcatcgggacaaactta 600 cactgcgcggtctcgggctgtgtttcgtgatcagatgtaaacgacattgtatttactegggtcacattcccaacgcaatggcgtgatcgacaaatacga 700 ccgaggcaaagtacatatttcacgacatctagtaacaagatgaggacaagtcaggtcctgtatccagaccggtccattctgattttacatttatcagta 800 tcatcagtaataaattggagggaattttgcgtcgttgttatatgatacgtatggctgcaatcaaagceccgaacaagatgctagcaccccatttttcc 900 ctctgctgtaagaatgcctcacatgtcagggacacttttggaatagcttgccattactgacgcaggcgcactacagtcagaccagacaaactgaaacca 1000 gtcactgaacggatagcaatgactagtaattgcatgatcatcttccactcgatctgttgtttatttcaatatggaaatacgggcaagatgaatatacaag 1100 accgcacatgctaatttcagttcgctacccgtcaacgcactaaaaaatcttcgtttgtttttcgaaaaaaatgctgtttcttttaattgtagtttggt 1200 aacaaagcaccgatcatcactgagcacaggtctgattcgctggaacatcaatgatttattttgagttttggctttagaagccgttaccaccgcgaaatgt 1300 taattgggtgttggatctattcataaaggggtcgtttcaattttgtgacctgaaacgttctcaacgtagtcaacctagacagccgtcaggaatcttcacc 1400 cgegaagaaagecagaagtgcttcatttctatgaaagacaaagacattccatttactaaatcgegtcttctacacacatgaatatcttttcgcattga 1500 tatttatgcgttctgatttatacaaaatttcgcaatgctgaatatggacaaaacgaaaagatcaaggataccattgccggaaaagtcgcagtgcggctgt 1600 gtagcggagcgtaaaatagtttccttgttgcattctacaagtaaggctgactgcgattggctcagtaaaccgcagctgtcaccgtcagtcagatgtcgg 1700 gacgagggggggggggagatgcacagattgtggtgtcaacatatcatggataggataggatagataggccatacgggtaggtagctttggctgcatatc 1800 ggaaggcaacatcttacaaattatccaaggatatttcttcttcagctttccttcacattatcatcaagatattgtatattttgtgtaataatta 1900 ttgaatgtatcatacatcgggcttgttcttcactcagtcatcggggatgttatctgatattgatgactttctgtaatatcagcactgttaaatattaa 2000 acagacattcaacataacatgcataacgtccccagtcggaggggggaggggagggacagaaactttcatacaaattaaagagtaatgtgaaaatcctca 2100 ctcagcagaactggaccagcttcacttcattgccatgtatagcagatccttcatggcactcactggagtatgtgaagacatttgtcagttccctgac 2200 agtgcacttgattacacttatcataagatctagcctatataaatcttggggaactctataaccgtccatcttgggtatgtagaagtcgtttggctgacca 2300 gagtggcgcattgctgtgacagcgtttgttttatcacattttctgaatcagccttgaaggaagcggcatgtcagaggtaggccattgttgactctagagg 2400 atcccaacgtattgcttttgacaatccggtacatgacagagatatttctgctgaccttcagtgccttgggcgtaaccgatgaaaaaccttttctctaaa 2500 acgccaactaattatgccgcttcaacggccctgtatgcggacccgtcagggggcagtttgggtggtgatcgtttacttccttctttctggtcagtcttg 2600 tcctcacacacaatgtgtgctgacgtattttggtaaatatcagccggtactgtctcggcttggtgccagagtcatgracaggcgggctaagtcaaccctg 2700 gaggagtgcagctcgctgtatcagctcgctcctggaggaccgaagtagtccgcatggggcgctgaagaaatctcaactccaggctaggcatgaccagcag 2800 ttggccacatccagctgtgaactttggctattgatgtgtataacaacacttcttctacattgtaaggaaactttaatgactgctgtgactttcctccctc 2900 caфTCGGACGACTATGTCAAGGCTCGGGTGATGTTCAAGGAGGAGCAGATCTCCG taagtcgggetgacacagtcacgtgtttcaggtgggaaattca 3000 aaacatggatgtgeggtgttttgtaaacaaataacattgataggagaatattcaacttcecctccategtcacctcattaccgtcgtcctcttcataa 3100 tcatcattctcaaccttattataactattcacctcatcattatcctcctcctcccattaccaccaattatcatcctcagcatcattctgatcataatcaa 3200 catcatcattatcatcatcatcatcaccatcatccacatcatcatcatcatccacatcatcacagtacagagttgcactttgttcccatacaaaatgttt 3300 gccatcgaattttcgactgtccttctaccgtctttctcagaattcaaatgacctttggcttcaagtctttcttacactttgtgtcttatatataatgaag 3400 gtcctgtcatggacaagactagttttatcatctttttgaaaggaaaagtattcaacgttattggttcagctgcggaaaggcttatttaaatcatttaa 3500 aatgtcctcctttggtgacattcaaggatagaacatctgtgaattctaaacgtcatggcatccataatgtgaatttaatccttcaacaccctatctctg 3600 tattgactaccaggaaaaaaaatccatttttttctatttgccetccaaccgacaatgagggaatcacatatatcattttcctttgcctttctaatgaaa 3700 tgtttctaaaca AGTTCAAGATGGCGTTTGACATGTTCGACGAGGATGGCGGTGGTGACATCAGCACTAAGGAGTTGGGCACGATCATGAAGAGGCTGG 3800 GCATGAGCATCTCCAGAGAGGAGCTGCAGCAGATGATCGACGAGGTGGACGAGGACG taagtctgtcccaactctcttcagtgggaaatgcaacaccgt 3900 taatctgtgtttggcgtcaagattactacacaggctttagatttagtcctctatagtcaaagtgcttggtatctcagacttgactcactgctgcagtttt 4000 tcgagtctatcgagtatatt tctatctgttaacadCCAGCGGTACCATCGACTTCGAGGAGTTCTTGGAGATGATGGCCAGGGCCATGCAGGACAGTGA 4100 GCGTGAGATTCCCGACGATGAGCTACGTGCAGCCTTCAGGTCTTGGACAAGAACGGAGATGGTTTCATCGACAAGGACGAGTTCCGGgttagtcatggt 4200 taactttatcttacagcatgtttaactgccatccaggccgcgcgattctgaatgtcattttccccgccagctcctaactagagattgtttacacaggcga 4300 gaaaagtgagccttcccatatatttggtgacaccaatgtgcttttggttgatttgattcctccattgatgatccttgtagtcatttgaatacctgtcctc 4400 cCccafGCCCTAGCATCAGAGTGCGCCGGTGATGACTTGACAGATGATGAGCTCCATGAGTTTATGGACGAGTACGACGGAAACAGGGACGGGAGGTTTG 4500 ACTATGAGG faagagccatttggcactgacgtcagctcatagcatggcatcatttccgtgtcaaattgcatacgtaaaacgttttggggtctatacg 4600 tgacgttttgggggtcgatcaatgcgtcacgtatgccagcctacgccacgtatggcaaaacgtacggatacgtgatgtacatatggttctgcaatttcc 4700 gtgtaaaattacgtacataaaaaacgttttgggggtccatacgtcacgtagtccaggctatacgtcacgtatggcatcacatatgtttgccatacgtc 4800 acgtactaaacgtgacgtacatatggtcctggcattttcgggtcgaaatatcgtactatcgaaaacgtcacgttacgtagatacaagggttgtgttaacg 4900 taatgtatgtacgccetcaagttatcataacgcattacgttaacataacgtagtcatagttaccataacgcattacgttaacgtaacatagtcctttac 5000 Gttaacgtaacgcatcacgttaacgtaacgtatgaaattatgcaaatgaggatactgacttacggtttctcgtttgtacttttatttgtgctatatgtca 5100 cataggacgttctagccaggcttcaaaaatttgtccgtactactttgtatccattggtactacttgtatccatggggtcacccattaatattgtgttc 5200 tgcggcctttaggttaataccaagccatacacaacgtaaactggtgacgtaaccagaacaccagaacacgtctattatagacgttcactctctagtgtat 5300 gtggagtttgtaacgtaacatacgtaacacaacgtaacatacgtaacattacgttaacgtggtacatttgatgctttatgtaaacgcgtaggacttgcat 5400 acgtacgtttgactcccaaacgtcacgtattcaccaaagaacgtgacgttttttacgtatgtaaattttgacacggaatgetgccatacacttcggat 5500 ggtttcaatgtttttgtcacatatcttggtctaaactgcggcgaagaacgacacgatatcccatgcactatgttgacaatagcgcagcactactagatag 5600 gagaactacgtatactcgatagttgaagccttgtgggtgagattgaagccatattgctgaaccatatccttgtatgattaattcaacttttcttcaccg 5700 gctttcaccacgaatgtgacgagaatatgttcagtgatttgtaacagggctctggaaggctttatcgactcataatctgattttaaagaatgtttttt 5800 tctgttacctcgacataggtggttttattagatctaaataagcaaagaaaaataaatttcatatctgaagcgaatctaaacatattcgacagccgta 5900 caaatgetgaaccttgcgtgactccatctatccatatttgaactgtacactgcaccgtaacgataagttttcttggactttegttagaacaaacatca 6000 ttctgaggtctgcccatttcgtaacctaagggccctgtcacacttgtgcgtacattcaagtgcgcatgagatccgcagtaactttggtttaagtaaatt 6100 ttgcggggaggaagttgttttctacttcgacccatcgttgtgcagtttggttatcaaaccaaagaacttacttcttcggcagcaaacttaacctaaacca 6200 aaaacatgctaatacgcaactcatgcgggcttgtgtgatcagcagactaccgtcaaaactgtttaaactgcgtttctcaccagaccttgtatcgtgca 6300 agtactgttcaggttcattatgaattttcccaatagtcgtgatcaactacgtacaagatgttatggaatgecggttgaatgtagtttctacacaatggt 6400 gtggttttccgctaatttttggcgacacctaagcggcgagcctgatggtaaagtagtgtgtgcagtctgcaagaattctaggaattgtacaggaatgtgt 6500

Fig. 4 (continued on next page) 
that of the genome (see below). These amino acid changes do not effect the $\mathrm{Ca}^{2+}$-binding motif.

The cDNA of $B$. floridae TnC is composed of $964 \mathrm{nu}-$ cleotides and the open reading frame is 495 nucleotides, encoding a protein of 164 amino acid residues including the initial Met, the same number as in $B$. lanceolatum $\mathrm{TnC}$ as shown in Fig. 1. The nucleotide sequence of these two cDNAs is $90 \%$ identical and, within the coding regions, there are 23 nucleotide substitutions reflecting 4 amino acid differences. These substitutions seems to have no effect on $\mathrm{Ca}^{2+}$ binding, suggesting that both $\mathrm{TnCs}$ can bind three $\mathrm{Ca}^{2+}$ per molecule (15). In the case of ascidian, two isoforms of $H$. roretzi $\mathrm{TnC}$, the larval and adult types, are produced by alternative splicing (14). However, in amphioxus $\mathrm{TnCs}$, the substitutions are not restricted to a particular region, suggesting that alternative splicing has not occurred. Thus these nucleotide and amino acid substitutions are supposed to result from a species difference, and the same $\mathrm{TnC}$ might be expressed in larval and adult amphioxus. These results seem to reflect the fact that ascidian undergoes metamorphosis during development, but amphioxus does not.

Preparation of the genomic DNA was prepared by the phenol-chloroform method produced an unacceptably high level of contamination by polysaccharides, and the genomic DNA was not digested with restriction enzymes. The polysaccharides were removed by passing the preparation through a DEAE-cellulose column, but the amount of recovered genomic DNA was less than $1 / 10$. This made it difficult to perform Southern analysis of EcoRI-digested genomic DNA, and the probe hybridized with only a single band (Fig. 2, ca. $3.0 \mathrm{kbp}$ ). This fragment seems to correspond to nucleotide positions 3541-6478 (Fig. 3a, indicated by the asterisk). According to the restriction enzyme map (Fig. 3), another fragment containing exons 1 and 2 should be detected. However, the length of exons 1 and 2 is relatively short, and the probe might not hybridize with the fragment under our conditions. Though Southern blot analysis of DNA digested with other restriction enzymes was not performed, no other band suggesting the possible existence of another $\mathrm{TnC}$ gene was observed. In addition, on each reaction of genomic PCR, only a single product derived from $\mathrm{TnC}$ gene is amplified. Thus the $\mathrm{TnC}$ gene seems to be present in a single copy in the genome of amphioxus.

Figure 4 shows the nucleotide sequence of the $B$. lanceolatum TnC gene, which was constructed from five overlapping fragments separately amplified by PCR as shown in Fig. 3. The genomic structure shows that it is composed of 8,101 bp and divided in 6 exons by 5 introns. All introns start with gt and end with ag, and according to the nomenclature of Kretsinger and Nakayama (21), the intron positions are $-17 / 0,1.01 / 1,2.13 / 1,3.24 / 0$, and $4.21 / 1 .^{3}$ There is no sequence discrepancy in the overlapping regions, and the nucleotide sequences of exons are exactly identical with that of cDNA. No exonic sequence is observed within intron 2 and 3 , suggesting that alternative splicing does not occur.

cDNAs of TnC Isoforms from the Frog, X. laevis-From the white muscle of the frog $X$. laevis, two distinct cDNAs encoding $\mathrm{fTnC}$ were detected. The longer isoform, named $\mathrm{fTnC} \alpha$, is composed of 1,090 nucleotides, and the shorter isoform, named $\mathrm{f} \operatorname{Tn} C \beta$, is composed of 801 nucleotides (Fig. 5a). Both cDNAs encode a protein of 163 amino acid residues, and the difference in length between them lies mainly in the length of the $3^{\prime}$-noncoding regions. The deduced amino acid residues of $\mathrm{f} \operatorname{TnC} \alpha$ and $\mathrm{fTnC} \beta$ are identical except that residue Arg-102 of $\mathrm{f} \operatorname{TnC} \alpha$ is changed to Cys-102 in $\mathrm{fTnC} \beta$. This substitution does not effect the $\mathrm{Ca}^{2+}$-binding motif. These isoforms show higher homology with each other than with the fTnC of another species of frog, $R$. esculenta (5), suggesting that the gene duplication might have occurred only in $X$. laevis or the ancestor of closely related species to Xenopus. In the genus Xenopus,

\footnotetext{
${ }^{3}$ The positions of introns are indicated according to the nomenclature of Kretsinger and Nakayama (21). The first number indicates the number of the EF-hand site sequentially numbered from $\mathrm{N}$ to $\mathrm{C}$. The second number (following the period) shows the number of the residue within the site, which is generally constructed from 29 residues. The last number (following the slash) is phase: 0 means the intron lies between triplet codons, 1 means between first and second nucleotides of the codon, and 2 means between second and third. For example, 4.21/1 means site IV, 21 st residue and phase $1 ;-17 / 0$ means phase 0,17 residues before the beginning of site $I ; 3+01 / 1$ means phase 1, 1 residue beyond site III, within the region between site III and IV.
}

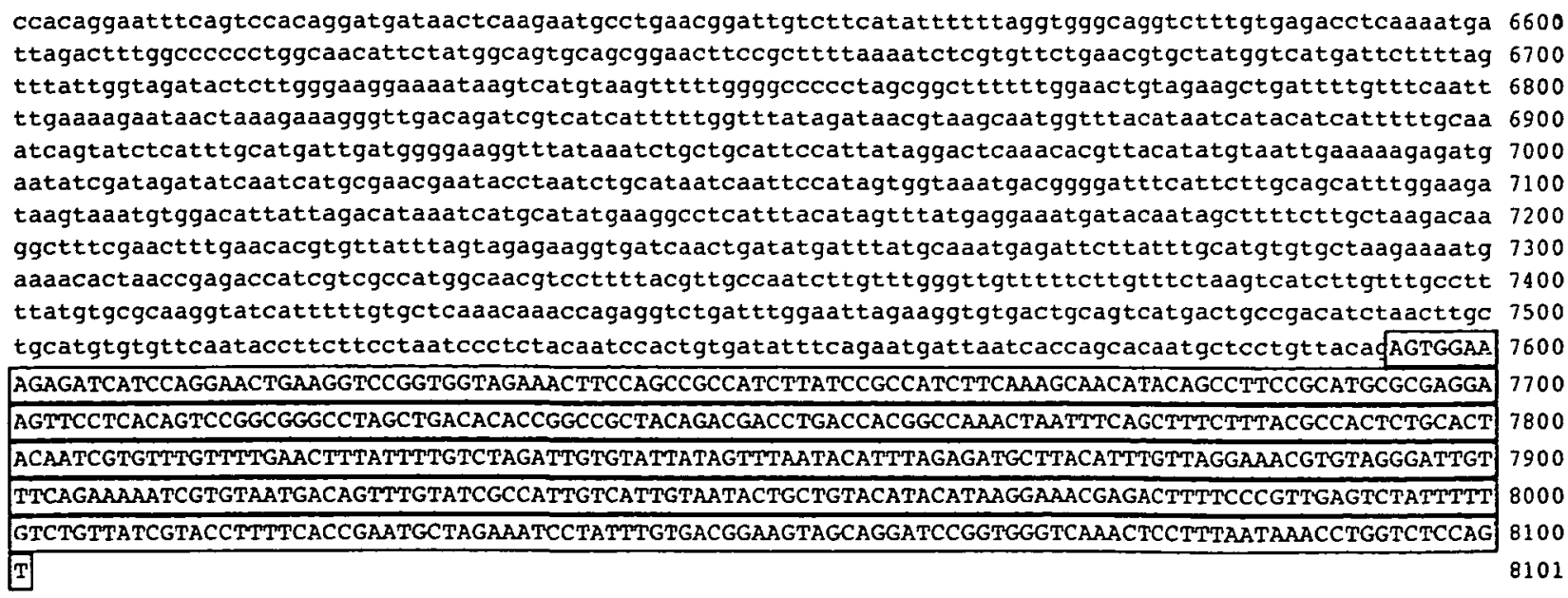

Fig. 4. Nucleotide sequence of the $B$. lanceolatum TnC gene. The exons are indicated by capital letters and boxed. The sequences of introns are shown in lower-case letters. 


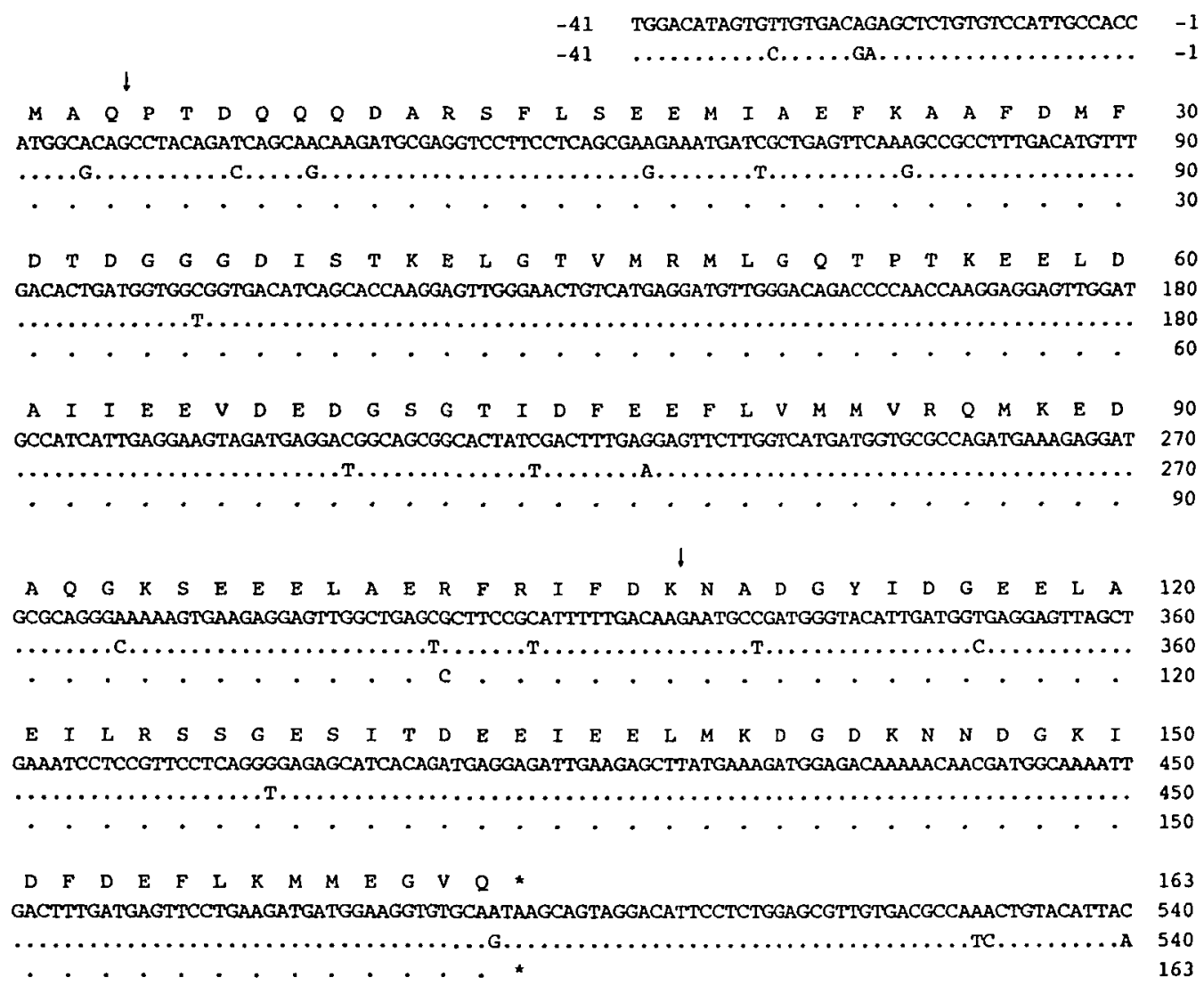

ACTGCGTCTTACATACTTTTCAGGAAGGGGCAAGTCACCCTGCTCTTTTCCTGTACCTCCCACAATCATCCTTGCTTCTGATGTGCACAT 630

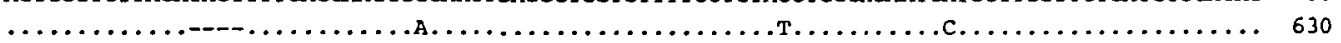

CACTCTCCACAGCCAACTTGCATCTTGCAGAGAACCTCTTAATTCACCGTTTACTCTCAGACTTTCCACCCTTTGCATTTTTCTCTGTAT 720

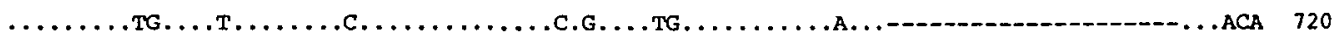

TTCTGACATATGTTATTTAT--AAGAAAAATACAAAGTGACCATTAAAACTATTAGTGAACCTTTATTATGTGTGGGCTGCATTCATAG 810 A. .T-........... TA..............................An 787

AAACTCCCGATCTAGCTGTGGTACAAAGCAAATGTCGCAGTACTTTTTTTCTCAACTCTCTTGTATAAAACAGCAATTATAGTTTTGGGG 900 CACAGCAGATAATGGCTACCCCCATATGCCACTCTAGAGAGCTGCCTACTCTGCCTAGTAGTAACACAGTGGAAAGCACTAATATATTTG 990

CATATCCGTTATTTTACATTCITACATTICAGCATGTAAATAAAGGGTGATGATTTTTGAn

1051

Fig. 5a

polyploid species are commonly observed (22), and the presence of two fTnC isoforms may arise from allelic variants of the pseudotetraploid $X$. laevis. The first intron of the fTnC $\alpha$ gene is composed of $439 \mathrm{bp}$, and inserted at $-18 / 0$ ( 6 bp downstream from the initiator ATG, data not shown). The intron inserted within site III coding region is composed of $138 \mathrm{bp}$, and positioned at $3.11 / 2$ (data not shown), the same position as the mammalian and avian $\mathrm{TnC}$ genes.

The Xenopus s/cTnC cDNA was isolated from heart muscle and found to consist of $1,528 \mathrm{bp}$ (Fig. 5b). The open reading frame is composed of 486 nucleotides and encodes a protein of 161 amino acid residues. This is the same length as the mammalian and avian s/cTnCs. The other cDNA encoding the $\mathrm{s} / \mathrm{cTnC}$ isoform was not detected. The intron within the site III coding region is composed of 1,242 bp and inserted at 3.11/2 (data not shown).

$c D N A s$ of TnC Isoforms from the Lamprey $E$. japonicus-The cDNA of the $E$. japonicus fTnC was isolated from the white muscle and found to consist of $892 \mathrm{nu}$ cleotides (Fig. 6a). The open reading frame is composed of 504 nucleotides and encodes a protein of 167 amino acid residues. The lamprey $\mathrm{f} \mathrm{TnC}$ is four residues longer than the avian and frog fTnCs, and the longest of all known verte. brate TnCs (Fig. 7). Two of four additional amino acid residues are located at the $\mathrm{N}$-terminus, and the other two residues at the C-terminal end. As in the other vertebrate TnC genes, the intron positioned at $3.11 / 2$ (ca. $1.8 \mathrm{kbp}$, data not shown) is also inserted in the Entosphenus fTnC gene. 
(b)

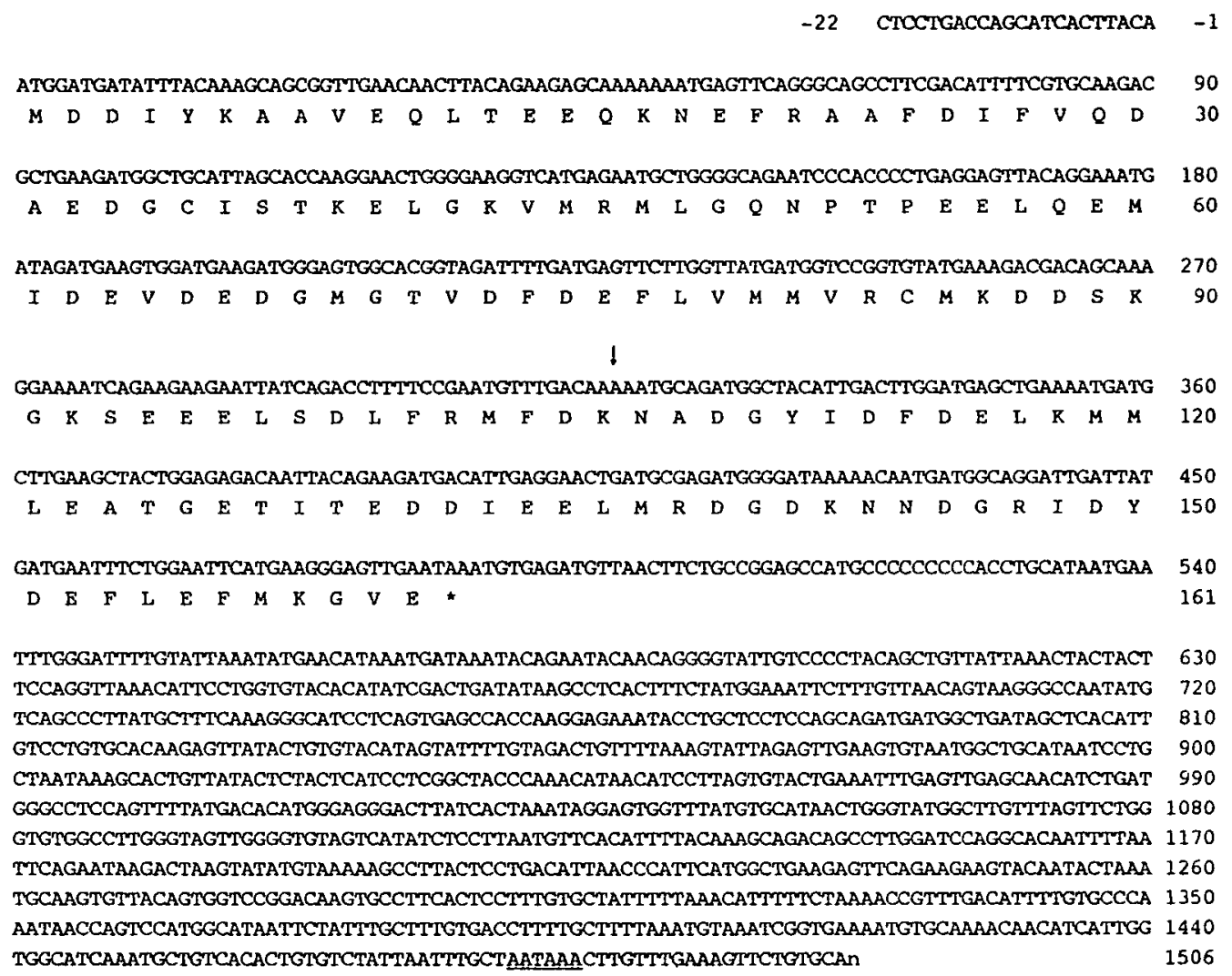

Fig. 5. cDNA and derived amino acid sequences of the $X$. laevis TnCs. a: Upper, $X$. laevis $\mathrm{f} \operatorname{TnC} \alpha \mathrm{cDNA}$ and the deduced amino acid sequences; lower, $X$. laevis $\mathrm{fTnC} \beta \mathrm{cDNA}$ and the deduced amino acid sequence. Identical nucleotides and amino acids to those in $\mathrm{fTnC} \alpha$ are indicated by dots (.). Gaps are inserted for maximal similarity and

The cDNA encoding the lamprey $\mathrm{s} / \mathrm{cTnC}$ was isolated from the heart muscle and found to consist of $1,346 \mathrm{bp}$ (Fig. $6 \mathrm{~b})$. The lamprey s/cTnC is composed of 162 amino acid residues, possessing an additional residue at the $\mathrm{N}$-terminus as compared with the other vertebrate $\mathrm{s} / \mathrm{cTnCs}$ (Fig. 7 ). For the lamprey s/cTnC gene, we were unable to amplify the site III coding region.

Evolution of the TnC Genes and Intron Mobility-From the above results, it is fairly certain that the protochordates possess a single $\mathrm{TnC}$ gene, while vertebrate species appear to possess two $\mathrm{TnC}$ isoforms. The constructed phylogenetic tree (Fig. 8) also suggests that the $\mathrm{TnC}$ gene duplication might have occurred in a vertebrate ancestor after the protochordate/vertebrate divergence. On the other hand, the duplication of the 3rd exon and expression of isoforms by alternative splicing might be a feature of the ascidian lineage.

The distributions of introns in the $\mathrm{TnC}$ genes of amphioxus, ascidian (14), and mammals (1-4) are listed in Table III. The positions of introns 2, 3, and 5 (placed at 1.01/1, $2.13 / 1$, and $4.21 / 1$ ) are identical in all genes. The first introns of amphioxus and mammal fTnCs are inserted at $-17 / 0$, and $\mathrm{s} / \mathrm{cTnCs}$ and ascidian $\mathrm{TnC}$ are at $-10 / 0$. However, in the case of $\mathrm{s} / \mathrm{cTnCs}$, the first intron is located 7 residues downstream of the initiation Met, but in the shown by bars (-). The typical polyadenylation signal (AATAAA) is underlined. The arrows indicate the positions of introns. $b: X$. laevis $\mathrm{s} / \mathrm{cTnC} \mathrm{cDNA}$ and the deduced amino acid sequences. The arrow indicates the position of an intron.

ascidian $\mathrm{TnC}$, as the $\mathrm{N}$-terminal amino acids are deleted compared to other TnCs (Fig. 7), the position of -10.0 is just after initiation codon ATG. The insertion of the first intron just after initiation codon is a common feature of the TnC superfamily (23), such as calmodulins $(24-26)$, myosin essential light chains $(27-31)$ and Spec $(32,33$, also see Table IV). Therefore, the position of the first intron of the ascidian $\mathrm{TnC}$ is assumed to be identical with the amphioxus and mammal fTnCs. The $\mathrm{N}$-terminal region (before site I) does not directly participate in $\mathrm{Ca}^{2+}$ binding, and some insertion/deletion may be permitted provided a flame sift or stop codon does not occur. The mechanism of the sliding of first introns may be junctional sliding (34), the reassignment of a single upstream or downstream splice junction.

On the other hand, intron 4 is placed at 3.24/0 in two protochordate $\mathrm{TnCs}$, and at $3.11 / 2$ in vertebrate fTnCs and $\mathrm{s} / \mathrm{cTnCs}$. Thus intron 4 of $\mathrm{TnC}$ may have originally been placed at 3.24/0 and have slid to 3.11/2 during the evolution from protochordate to vertebrate. The gene duplication might have occurred following this slide.

The intron positions of $\mathrm{TnC}$ superfamily genes are listed in Table IV. As mentioned before, the first introns of TnC superfamily genes are generally inserted at just after the initiation codon. The positions of intron $2(1.01 / 1)$ and 
(a)

-76 ACTCAGGCAAGAAGGTTTGAOCAGCTAGGCGGTCCTGAGTGTTGGTAGAAATCAAGACAACCCCTTACCAAGTACC -1

ATGGGAGACGAGGTCGCGACAGAGSCACAGCACGATGCTCGTGCCTACCTCAACGAAGAACAGATCGCTGAGTTCAAGGCTOCCTTICGAC 90

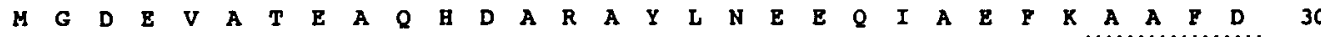

ATGTTCGACGCGGACGTGGCGGIGACATCAGCACCAGCGAGCTGGGCAGGTGATGAAGCTGCTGGGACAGAACCCCACCAAGGAGGAG 180

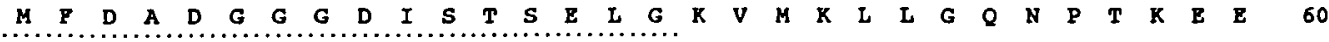

CTOGACGCCATCATTGAGGAGGTGGACGAGGATGGCAGCGGCACGATCGACTTCGAGGAGTTCCTGGTGATGATGGTGCGGCAGATGAAG 270 $\begin{array}{lllllllllllllllllllllllllllllllll}\text { L } & D & A & \text { I } & \text { I } & \text { E } & \text { E } & \text { V } & \text { D } & \text { E } & \text { D } & \text { G } & \text { S } & G & \text { T } & \text { I } & \text { D } & \text { F } & \text { E } & \text { E } & \text { F } & \text { L } & \text { V } & \text { M } & \text { M } & \text { V } & \text { R } & \text { Q } & \text { M } & \text { K } & 90\end{array}$

$\downarrow$

GAOGAGTCGGCCGOCCAGACGGAGGAGGAGTTGGCAGAGOCGTTCCGCATCCTCGACACGAACGCCGATGGCTACATCGATCGGGATGAG 360 $\begin{array}{lllllllllllllllllllllllllllllll}\mathbf{E} & \mathbf{E} & \mathbf{S} & \mathbf{A} & \mathbf{G} & \mathbf{Q} & \mathbf{T} & \mathbf{E} & \mathbf{E} & \mathbf{E} & \mathbf{L} & \mathbf{A} & \mathbf{E} & \mathbf{A} & \mathbf{F} & \mathbf{R} & \mathbf{I} & \mathbf{L} & \mathbf{D} & \mathbf{T} & \mathbf{N} & \mathbf{G} & \mathbf{D} & \mathbf{G} & \mathbf{Y} & \mathbf{I} & \mathbf{D} & \mathbf{R} & \mathbf{D} & \mathbf{E} & 120\end{array}$

CTGAAGGACATCCTGCTGAACACGGGCGAGAACGTCACGGACCTIGAGATGGATGAGCTGATGAAGATGGCGACAAGAACTGCGACGGG 450 $\begin{array}{llllllllllllllllllllllllllllllll}\text { L. } & \text { K } & \text { D } & \text { I } & \text { L } & \text { L } & \text { N } & \text { T } & \text { G } & \text { E } & \text { N } & \text { V } & \text { T } & \text { D } & \text { L } & \text { E } & \text { M } & \text { D } & \text { E } & \text { L } & \text { M } & \text { K } & \text { D } & \text { G } & \text { D } & \text { K } & \text { N } & \text { C } & \text { D } & \text { G } & 150\end{array}$ CGTCTEGACTTTGACGAGTTCCTGAAGATGATGGAGGGCATCGCTGCGTCTTGATCAGGTGGACCGTGGACCGACTCTTCCCCAGAACCC 540

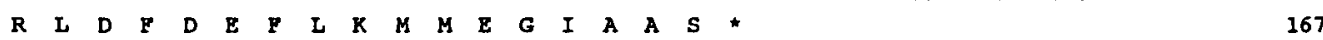

CCTTCCCCTGTAATCCCCGTCTGATGAGTCCCATCTCTTGTCTGTGTGAACCCATGCAACAACCCCAGTTGCTTAATECCACCGGTTTCAG 630 GATGTCGTATACAACCACACCAACTTCACTGCCGTACATTGTGCCAGCTCAGAAAAGGGTAACTTTTGATTTGTCCCAAAATGCTTCGT 720 GGOCACTCGGTAGCATCTAGAAGAGAACAATTATGTTTTCACGACCACAAAGCAAGCGCTTGTCAAGTCAACATCGTAAATAAAGTATTC 810 AGGGCAN

(b)

-33 GACTGCCCACGAAACAAATCGGACCGGGCAGCC -1

ATGSCGGAAGACGTGGATAGAGCGGCCGTAGAGCAGCTGACGGAAGAGCAAAAAAAAAGAATTCCGOGCCGCCTTTGACATCTTCGTGCAA 90

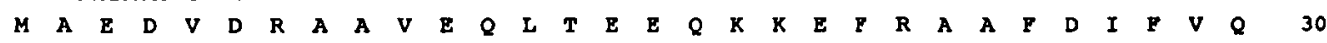

GACGCCGAGGATGGCTGCATCACCACCAAGGACCTGGGGAAGGTGCTGCGATGTTGGGGCAGAACCCCTCGCCAGACGAGCTCCAOGAG 180 $\begin{array}{lllllllllllllllllllllllllllllllll}\text { D A } & \text { E } & \text { D } & G & C & I & S & \text { T } & \text { K } & \text { E } & \text { L } & G & \text { K } & \text { V } & \text { L } & \text { R } & \text { M } & \text { L } & \text { G } & \text { Q } & \text { N } & \text { P } & \text { S } & \text { P } & \text { D } & \text { E } & \text { L } & \text { Q } & \text { E } & 60\end{array}$

ATGATTGACGAGGTGGACGAAGATGGCAGCGGCACCGTGGACTTCGAGGAGTTCCTCATCATGATGGTGCGCAGCATGAAAGAGGAGAGC 270 $\begin{array}{lllllllllllllllllllllllllllllll}M & I & D & \text { B } & \text { V } & \text { D } & \text { E } & \text { D } & G & \text { S } & G & \text { T } & \text { V } & \text { D } & \text { F } & \text { D } & \text { E } & \text { F } & \text { L } & \text { I } & \text { M } & \text { M } & \text { V } & \text { R } & \text { S } & \text { M } & \text { K } & \text { E } & \text { E } & \text { S } & 90\end{array}$

AAGGGGAAGTCAGAAGAGGAGCTGAGCGAACTCTACCGCATGTTTGACAAAAACGTTGACOCCTACATCGATCTGGAGGACCTCAAOGTG 360 $\begin{array}{llllllllllllllllllllllllllllllll}\text { K } & G & \text { K } & \text { S } & \text { E } & \text { E } & \text { E } & \text { I } & \text { S } & \text { E } & \text { L } & \text { Y } & \text { R } & \text { M } & \text { F } & \text { D } & \text { K } & \text { N } & \text { G } & \text { D } & \text { G } & \text { Y } & \text { I } & \text { D } & \text { L } & \text { E } & \text { E } & \text { L } & \text { K } & \text { V } & 120\end{array}$

ATGCTGCACGCCACGGGGAGGACATCACAGACGACGATATCGAGGAGCTCTTTGCGGACGGAGACAAAAACGCCGACGGATTTATCGAT 450

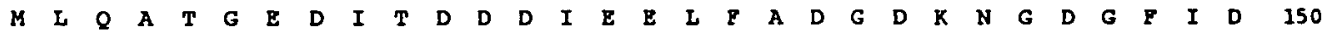

TACGACGAATTCATCGAATTCATGAAGGGAGTGGATTAATGGGAATCTTCCGTATACCCCATCGGATATTACGATAACATCTACAACAAC 540 $\begin{array}{llllllllllllllll}\text { Y } & D & E & F & M & E & F & M & K & G & V & E & * & 162\end{array}$

AACAAACAACCCAAAATACGACGTGCATTAATACACGAGTGAAACGAAAACTATGCCTAGOCGACGATAAGAGCCGTACAACATAGCCTT 630 GGCATAGTGTGGCTTCTTCAACAACTATATCGCCTACACATACATATGTAAATCATTACAACAGGGCCCTTGAGTAAGTTAACAATOGCT 720 TGGATCGAGTTGGTCCTCCGTTTECACCTTTGCTTTCGTGAAAAAACGCAACCCAGAAGGACGCATGCGGCTCTTATCTAGTGGCTEGCT 810 CCACGCGAGCTTGATGACTTTGTGAACGAGGTTAACAAACACAAACGCAGAGGAAACATTGTGAAGTTACTTTCGCOGGCGTGCCCOCTT 900 TCGAGCGCTAACGATGTCCTGAAAATAATTTTTGAGTCGTTTTCTTTCATTGTTATTATTGTTAACGAAGCGTCAATATTGTGTCGATAT 990 CCCGACGTTCTGTAGTTACTAGAGAAGACCTCCCСETTTTCATGTGGTCGCGTGTGAGGATGTACGCGCTCTGTGTAACGTGTTGGACAT 1080 ACAGATGACATCAACGCGAAGTCGAGAGAATCTGGTAAATCCAGAAACAGAATTCTTCCAGTCATAACAACCAATTGATGGCGTTTCTGG 1170 TTTATGTTGAAATACAATGTTATGTACAATTTTACACTGTAGGTACCGCGTACGATTATGTTATACAGATGAGATTGGTCAATTTTATAA 1260 CTOCTCGTTTCAAGAACTAAOCCTGTGTAATAAATATATTGTACGTGACTTTAN

1313

Fig. 6. cDNA and derived amino acid sequences of the $E$. japonicus TnCs. a: $E$. japonicus fTnC cDNA and the derived amino acid sequences. The broken-underlined peptides were determined directly by use of an automated protein sequencer. b: $E$. japonicus
s/cTnC cDNA and the derived amino acid sequences. The typical polyadenylation signal (AATAAA) is underlined. The arrow indicates the position of an intron. 
site I

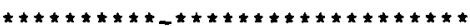

Buman $f$ Xenopus $f$ Lamprey $f$ Euman $\mathrm{s} / \mathrm{c}$ Xenopus $\mathrm{s} / \mathrm{c}$ Lamprey s/c Amphioxus Ascidian

\begin{abstract}
----MTDQQAEARSYLSEEMIAEFRAAFDMFD-ADGGGDISVRELGTVMRMLGQTPTREELDAIIEEVDEDGSGTIDFEEFLVMMVRQ 83 --MAQPTDQQQDARSFLSEEMIAEFRAAFDMFD-TDGGGDISTRELGTVMRMLGQTPTREELDAI IEEVDEDGSGTIDFEE FLVMMVRQ 86 MGDEVATEAQEDARAYLNEEQIAEFRAAFDMFD-ADGGGDISTSELGKVMRLLGQNPTREELDAIIEEVDEDGSGTIDFEEFLVMMVRQ 88 ----MDDIYRAAVEQLTEEQKNEFRAAFDIFVLGAEDGCISTRELGKVMRMLGQNPTPEELQEMIDEVDEDGSGTVDFDEFLVMMVRC 84 ----MDDI YRAAVEQLTEEQRNE FRAAFDIFVQDAEDGCISTRELGKVMRMLGQNPTPEELQEMIDEVDEDGMGTVDFDEFLVMMVRC 84 - - MAEDVDRAAVEQLTEEQKKEFRAAFDIFVQDAEDGCISTKELGKVIRMLGQNPSPDELQEMIDEVDEDGSGTVDFDEFLIMMVRS 85 ----MSDDYVKARVMFKEEQISEFKMAFDMFD-EDGGGDISTRELGTIMRRLGMSISREELQQMIDEVDEDASGTIDFEEFLEMMARA 82 ----------MVEALTEDQRSEFRTCFDIFVEDTEDGTITARELGKLMRMLGQNPSEQELKEMVEEVDLDGSGTIDFEEFCLMMYRQ 79
\end{abstract}

$$
\text { site III }
$$

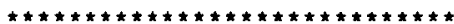

$\begin{array}{ll}\text { Euman } & f \\ \text { Xenopus } & f \\ \text { Lamprey } & f \\ \text { Euman } & s / c \\ \text { Xenopus } & \mathrm{s} / \mathrm{c} \\ \text { Lamprey } & \mathrm{s} / \mathrm{c} \\ \text { Amphioxus } \\ \text { Ascidian }\end{array}$

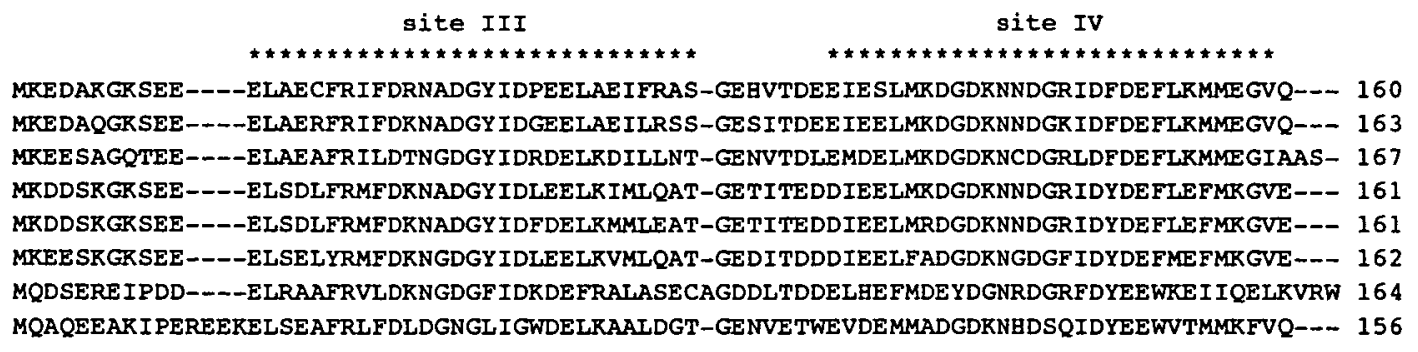

site IV

MREESRGRSEE-_-_ELSELYRMFDKNGDGY IDLEELKVMLOAT-GEDITDDDIEELFADGDKNGDGFIDYDEFMEFMRGVE-- - 162

MQAQEEAR I PEREERELSEAFRLFDLDGNGL I GWDELRAALDGT-GENVETWEVDEMMADGDKNHDSQIDYEEWVTMMRFVQ-- - 156

Fig. 7. Alignment of the amino acid sequences of cordate TnCs. The alignment of amino acids mainly follows the alignment of Takagi $e t$ al. (15). The four EF-hand sites (site I-site IV) are indicated by asterisks (*). For the ascidian, only the larval TnC was aligned.

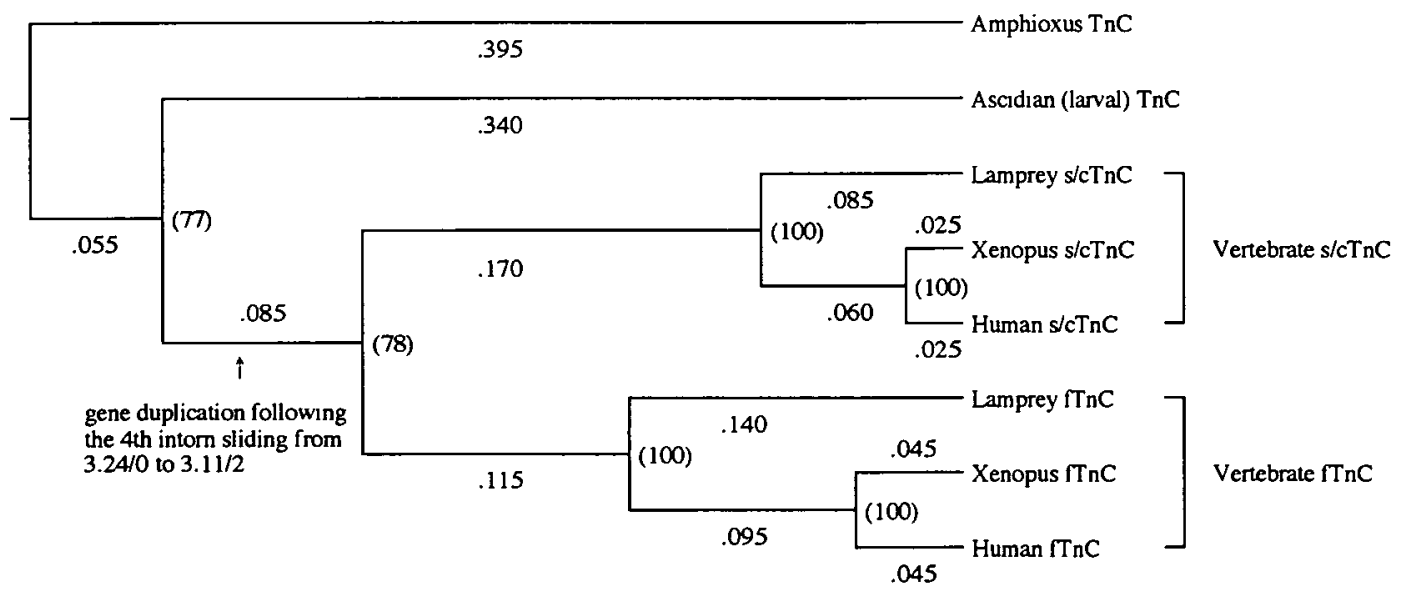

Fig. 8. A phylogenetic tree of cordate TnCs constructed from the sequences aligned in Fig. 7. The rooted tree was produced with the PHYLIP package (35) and UPGMA method was used. The numbers added to the branches show the length of each branch, and the parenthesized numbers at the forks indicate the percentage of 100 bootstrap resamplings that support these topological elements.

TABLE III. Localization of introns of amphioxus, ascidian, and mammalian TnC genes.

\begin{tabular}{llllll}
\hline Species (type) & \multicolumn{5}{c}{ Introns position and phases ${ }^{\mathrm{a}}$} \\
\hline Amphioxus & $-17 / 0^{\mathrm{b}}$ & $\mathbf{1 . 0 1 / 1}$ & $\mathbf{2 . 1 3 / 1}$ & $3.24 / 0$ & $\mathbf{4 . 2 1 / 1}$ \\
Ascidian & $-10 / 0^{\mathrm{b}}$ & $\mathbf{1 . 0 1 / 1}$ & $\mathbf{2 . 1 3} / 1$ & $3.24 / 0$ & $\mathbf{4 . 2 1} / 1$ \\
$\begin{array}{c}\text { Human/mouse } \\
\text { (fTnC) }\end{array}$ & $-17 / 0^{\mathrm{b}}$ & $\mathbf{1 . 0 1 / 1}$ & $\mathbf{2 . 1 3 / 1}$ & $3.11 / 2$ & $\mathbf{4 . 2 1 / 1}$ \\
$\begin{array}{c}\text { Human/mouse } \\
\text { (s/cTnC) }\end{array}$ & $-10 / 0^{\mathrm{c}}$ & $\mathbf{1 . 0 1 / 1}$ & $\mathbf{2 . 1 3 / 1}$ & $3.11 / 2$ & $\mathbf{4 . 2 1 / 1}$ \\
\hline
\end{tabular}

$\overline{{ }^{a}}$ Introns are designated according to Kertsinger and Nakayama (21), related to EF-hand domains. Those with identical positions in all genes are shown in bold. 'Just after initiator ATG. ${ }^{\mathrm{c}} 21 \mathrm{bp}$ downstream after initiator ATG.

intron $5(4.21 / 1)$ are also highly conserved among members of the TnC superfamily. The intron 3 positions are slightly different between subfamilies, but the phases are identical.
However, the positions of intron 4 are not conserved at all between subfamilies. Although the sliding mechanism is unknown, intron 4 of the $\mathrm{TnC}$ superfamily might have slid more easily than the other introns.

We wish to thank Dr. L.Z. Holland of Scripps Institution of Oceanography, University of California San Diego, for providing us with the B. floridae larval cDNA library.

\section{REFERENCES}

1. Parmacek, M.S. and Leiden, J.M. (1989) Structure and expression of the murine slow/cardiac troponin C gene. J. Biol. Chem. 264, 13217-13225

2. Gahlmann, R. and Kedes, L. (1990) Cloning, structural analysis, and expression of the human fast twitch skeletal muscle troponin C gene. J. Biol. Chem. 265, 12520-12528

3. Schreier, T., Kedes, L., and Gahlmann, R. (1990) Cloning, 
TABLE IV. The intron positions of TnC superfamily genes (based largely on Ref. 21).

\begin{tabular}{llllll}
\hline $\begin{array}{l}\text { Subfamily } \\
\text { species (type) }\end{array}$ & \multicolumn{5}{c}{ Positions of introns $^{\mathrm{a}}$} \\
\hline TnC & & & & & \\
Human(f) & $-17 / 0(\mathrm{M})$ & $1.01 / 1$ & $2.13 / 1$ & $3.11 / 2$ & $4.21 / 1$ \\
Human(s/c) & $-10 / 0$ & $1.01 / 1$ & $2.13 / 1$ & $3.11 / 2$ & $4.21 / 1$ \\
Amphioxus & $-17 / 0(\mathrm{M})$ & $1.01 / 1$ & $2.13 / 1$ & $3.24 / 0$ & $4.21 / 1$ \\
Ascidian & $-10 / 0(\mathrm{M})$ & $1.01 / 1$ & $2.13 / 1$ & $3.24 / 0$ & $4.21 / 1$ \\
Calmodulin & & & & & \\
Human(III) & $-10 / 0(\mathrm{M})$ & $1.01 / 1$ & $2.13 / 1$ & $3.12 / 0$ & $4.21 / 1$ \\
Rat(I,III) & $-10 / 0(\mathrm{M})$ & $1.01 / 1$ & $2.13 / 1$ & $3.12 / 0$ & $4.21 / 1$ \\
Rat(II) & $-10 / 0(\mathrm{M})$ & $1.01 / 1$ & - & $3.12 / 0$ & $4.21 / 1$ \\
Chicken & $-10 / 0(\mathrm{M})$ & $1.01 / 1$ & $2.13 / 1$ & $3.12 / 0$ & $4.21 / 1$ \\
Myosin essential light chain & & & & \\
Human & $-09 / 0(\mathrm{M})$ & $1.01 / 1$ & $2.12 / 1$ & $3+01 / 0$ & $4.21 / 1$ \\
Rat(L1) & $-09 / 0(\mathrm{M})$ & $1.01 / 1$ & $2.12 / 1$ & $3+01 / 0$ & $4.21 / 1$ \\
Rat(L4) & $-08 / 0(\mathrm{M})$ & $1.01 / 1$ & $2.12 / 1$ & $3+01 / 0$ & $4.21 / 1$ \\
Chicken(L1) & $-09 / 0(\mathrm{M})$ & $1.01 / 1$ & $2.12 / 1$ & $3+01 / 0$ & $4.21 / 1$ \\
Chicken(L3) & $-08 / 0(\mathrm{M})$ & $1.01 / 1$ & $2.12 / 1$ & $3+01 / 0$ & $4.21 / 1$ \\
Spec & & & & & \\
Sea urchin & $-12 / 0(\mathrm{M})$ & $1.01 / 1$ & $2.13 / 1$ & $3.18 / 2$ & $4.21 / 1$ \\
Parvalbumin & & & & & \\
Human & - & - & $2.11 / 1$ & $3.23 / 2$ & $4.21 / 1$ \\
Rat & - & - & $2.11 / 1$ & $3.23 / 2$ & $4.21 / 1$ \\
\hline
\end{tabular}

${ }^{a}(\mathrm{M})$ shows the intron is inserted just after the initiation codon, ATG

$(-)$ shows the absence of intron.

structural analysis, and expression of the human slow twitch skeletal muscle/cardiac troponin $\mathrm{C}$ gene. J. Biol. Chem. 265, 21247-21253

4. Parmacek, M.S., Bengur, A.R., Vora, A.J., and Leiden, J.M. (1990) The structure and regulation of expression of the murine fast skeletal troponin C gene. J. Biol. Chem. 265, 15970-15976

5. van Eerd, J.-P., Capony, J.-P., Ferraz, C., and Pechere, J.-F. (1978) The amino-acid sequence of troponin $\mathrm{C}$ from frog skeletal muscle. Eur. J. Biochem. 91, 231-242

6. Francois, J.-M., Gerday, C., Prendergast, F.G., and Potter, J.D. (1993) Determination of the $\mathrm{Ca}^{2+}$ and $\mathrm{Mg}^{2+}$ affinity constants of troponin $\mathrm{C}$ from eel skeletal muscle and positioning of the single tryptophan in the primary structure. J. Muscle Res. Cell Motil. 14, 585-593

7. Moyes, C.D., Borgford, T., LeBlanc, L., and Tibbits, G.F. (1996) Cloning and expression of salmon cardiac troponin C: titration of the low-affinity $\mathrm{Ca}^{2+}$-binding site using a tryptophan mutant. Biochemistry 35, 11756-11762

8. Satoh, N. (1994) Developmental Biology of Ascidian, Cambridge University Press, New York

9. Shinohara, Y. and Konishi, K. (1982) Ultrastructure of the bodywall muscle of the ascidian Halocynthia roretzi: Smooth muscle cell with multiple nuclei. J. Exp. Zool. 221, 137-142

10. Terakado, K. and Obinata, T. (1987) Structure of multinucleated smooth muscle cells of the ascidian Halocynthia roretzi. Cell Tissue Res. 247, 85-94

11. Kalk, M. (1970) The organization of a tunicate heart. Tissue Cell 2, 99-118

12. Holland, L.Z., Pace, D.A., Blink, M.L., Kene, M., and Holland, N.D. (1995) Sequence and expression of amphioxus alkali myosin light chain (AmphiMLC-alk) throughout development: implications for vertebrate myogenesis. Dev. Biol. 171, 665-676

13. Endo, T. and Obinata, T. (1981) Troponin and its components from ascidian smooth muscle. J. Biochem. 89, 1599-1608

14. Yuasa, H.J., Sato, S., Yamamoto, H., and Takagi, T. (1997) The structure of ascidian, Halocynthia roretzi troponin $\mathrm{C}$ gene. $J$. Biochem. 121, 671-676

15. Takagi, T., Petrova, T., Comte, M., Kuster, T., Heizmann, C.W., and Cox, J.A. (1994) Characterization and primary structure of amphioxus troponin C. Eur. J. Biochem. 221, 537-546
16. Chomczynski, P. and Sacchi, N. (1987) Single-step method of RNA isolation by acid guanidium thiocyanate-phenol-chloroform extraction. Anal. Biochem. 162, 156-159

17. Saiki, R.K., Gelfand, D.H., Stoffel, S., Scharf, S.J., Higuchi, R., Horn, G.T., Mullis, K.B., and Erlich, H.A. (1988) Primer-directed enzymatic amplification of DNA with a thermostable DNA polymerase. Science $239,487-491$

18. Takagi, T. and Konishi, K. (1983) Amino acid sequence of troponin $\mathrm{C}$ obtained from ascidian (Halocynthia roretzi) body wall muscle. J. Biochem. 94, 1753-1760

19. Yuasa, H.J., Sato, S., Yamamoto, H., and Takagi, T. (1997) Primary structure of Troponin I isoforms from the ascidian Halocynthia roretzi. J. Biochem. 122, 374-380

20. Frohman, M.A., Dush, M.K., and Martin, G.R. (1988) Rapid production of full-length $\mathrm{cDNAs}$ from rare transcripts: amplification using a single gene-specific oligonucleotide primer. Proc. Natl. Acad. Sci. USA 85, 8998-9002

21. Kretsinger, R.H. and Nakayama, S. (1993) Evolution of EF-hand calcium-modulated proteins. IV. Exon shuffling did not determine the domain compositions of EF-hand proteins. J. Mol. Evol. 36, 477-488

22. Kobel, H.R. and Du Pasquier, L. (1986) Genetics of polyploid Xenopus. Trends Genet. 2, 310-315

23. Carpenter, C.D., Bruskin, A.M., Hardin, P.E., Keast, M.J., Anstrom, J., Tyner, A.L., Brandhorst, B.P., and Klein, W.H. (1984) Novel proteins belonging to the troponin C superfamily are encoded by a set of mRNA in sea urchin embryos. Cell 36, 663-671

24. Nojima, H. and Sokabe, H. (1987) Structure of a gene for rat calmodulin. J. Mol. Biol. 193, 439-445

25. Nojima, H. (1989) Structural organization of multiple rat calmodulin genes. J. Mol. Biol. 208, 269-282

26. Koller, M., Schnyder, B., and Strehler, E.E. (1990) Structural organization of the human CaMIII calmodulin gene. Biochim. Biophys. Acta 1087, 180-189

27. Nabeshima, Y., Fujii-Kuriyama, Y., Muramatsu, M., and Ogata, K. (1984) Alternative transcription and two modes of splicing result in two myosin light chains from one gene. Nature 308, 333338

28. Periasamy, M., Strehler, E.E., Garfinkel, L.I., Gubits, R.M., Ruiz-Opazo, N., and Nadal-inard, B. (1984) Fast skeletal muscle myosin light chains 1 and 3 are produced from a single gene by a combined process of differential RNA transcription and splicing. J. Biol. Chem. 259, 13595-13604

29. Robert, B., Daubas, P., Akimenko, M.-A., Cohen, A., Garner, I., Guenet, J.-L., and Buckingham, M. (1984) A single locus in the mouse encodes both myosin light chains 1 and 3 , a second locus corresponds to a related pseudogene. Cell 39, 129-140

30. Lenz, S., Lohse, P., Seidel, U., and Arnold, H.-H. (1989) The alkali light chains of human smooth and nonmuscle myosins are encoded by a single gene. J. Biol. Chem. 264, 9009-9015

31. Henderson, S.A., Spencer, M., Sen, A., Kumar, C., Siddiqui, M. A.Q., and Chien, K.R. (1989) Structure, organization, and expression of the rat cardiac myosin light chain-2 gene. J. Biol. Chem. 264, 18142-18148

32. Hardin, S.H., Carpenter, C.D., Hardin, P.E., Bruskin, A.M., and Klein, W.H. (1985) Structure of the Spec1 gene encoding a major calcium-binding protein in the embryonic ectoderm of the sea urchin, Strongylocentrotus purpuratus. J. Mol. Biol. 186, 243255

33. Hardin, P.E., Angerer, L.M., Hardin, S.H., Angerer, R.C., and Klein, W.H. (1988) Spec2 genes of Strongylocentrotus purpuratus. J. Mol. Biol. 202, 417-431

34. Craik, C.S., Rutter, W.J., and Fletterick, R. (1983) Splice junctions: association with variation in protein structure. Science 220, 1125-1129

35. Felsenstein, J. (1993) PHYLIP (Phylogeny Inference Package) version 3.5c. Distributed by the author. Department of Genetics, University of Washington, Seattle 